University of Nebraska - Lincoln

DigitalCommons@University of Nebraska - Lincoln

Nebraska Cooperative Fish \& Wildlife Research Nebraska Cooperative Fish \& Wildlife Research Unit -- Staff Publications

2006

\title{
LIFE-HISTORY AND ECOLOGICAL CORRELATES OF GEOGRAPHIC VARIATION IN EGG AND CLUTCH MASS AMONG PASSERINE SPECIES
}

\author{
Thomas E. Martin \\ University of Montana - Missoula, tom.martin@umontana.edu \\ R. D. Bassar \\ University of Montana - Missoula \\ S. K. Bassar \\ University of Montana - Missoula \\ J. J. Fontaine \\ University of Montana - Missoula, jfontaine2@unl.edu \\ P. Lloyd \\ University of Cape Town \\ See next page for additional authors \\ Follow this and additional works at: https://digitalcommons.unl.edu/ncfwrustaff \\ Part of the Other Environmental Sciences Commons
}

Martin, Thomas E.; Bassar, R. D.; Bassar, S. K.; Fontaine, J. J.; Lloyd, P.; Mathewson, H. A.; Niklison, A. M.; and Chalfoun, A., "LIFE-HISTORY AND ECOLOGICAL CORRELATES OF GEOGRAPHIC VARIATION IN EGG AND CLUTCH MASS AMONG PASSERINE SPECIES" (2006). Nebraska Cooperative Fish \& Wildlife Research Unit -- Staff Publications. 57.

https://digitalcommons.unl.edu/ncfwrustaff/57

This Article is brought to you for free and open access by the Nebraska Cooperative Fish \& Wildlife Research Unit at DigitalCommons@University of Nebraska - Lincoln. It has been accepted for inclusion in Nebraska Cooperative Fish \& Wildlife Research Unit -- Staff Publications by an authorized administrator of DigitalCommons@University of Nebraska - Lincoln. 


\section{Authors}

Thomas E. Martin, R. D. Bassar, S. K. Bassar, J. J. Fontaine, P. Lloyd, H. A. Mathewson, A. M. Niklison, and A. Chalfoun 


\title{
LIFE-HISTORY AND ECOLOGICAL CORRELATES OF GEOGRAPHIC VARIATION IN EGG AND CLUTCH MASS AMONG PASSERINE SPECIES
}

\author{
Thomas E. Martin, ${ }^{1,2}$ R. D. Bassar, ${ }^{1,3,4}$ S. K. Bassar, ${ }^{1,4,5}$ J. J. Fontaine, ${ }^{1,6}$ P. Lloyd, $, 1,7,8$ \\ H. A. Mathewson, ${ }^{1,9,10}$ A. M. Niklison, ${ }^{1,11}$ A. Chalfoun ${ }^{1,12}$ \\ ${ }^{1}$ U.S. Geological Survey, Montana Cooperative Wildlife Research Unit, University of Montana, Missoula, Montana 59812 \\ ${ }^{2}$ E-mail: tom.martin@umontana.edu \\ ${ }^{3}$ E-mail: rdbassar@yahoo.com \\ ${ }^{5}$ E-mail: myioborus@yahoo.com \\ ${ }^{6}$ Email: joseph.fontaine@umontana.edu \\ ${ }^{7}$ Percy FitzPatrick Institute of African Ornithology, Department of Science and Technology, National Research Foundation, \\ Centre of Excellence, University of Cape Town, Rondebosch 7701, South Africa \\ ${ }^{8}$ E-mail: plloyd@botzoo.uct.ac.za \\ ${ }^{9}$ E-mail: heatherm@unr.edu \\ ${ }^{11}$ E-mail: alina.niklison@mso.umt.edu \\ ${ }^{12}$ E-mail: anna.chalfoun@umontana.edu
}

\begin{abstract}
Broad geographic patterns in egg and clutch mass are poorly described, and potential causes of variation remain largely unexamined. We describe interspecific variation in avian egg and clutch mass within and among diverse geographic regions and explore hypotheses related to allometry, clutch size, nest predation, adult mortality, and parental care as correlates and possible explanations of variation. We studied 74 species of Passeriformes at four latitudes on three continents: the north temperate United States, tropical Venezuela, subtropical Argentina, and south temperate South Africa. Egg and clutch mass increased with adult body mass in all locations, but differed among locations for the same body mass, demonstrating that egg and clutch mass have evolved to some extent independent of body mass among regions. A major portion of egg mass variation was explained by an inverse relationship with clutch size within and among regions, as predicted by life-history theory. However, clutch size did not explain all geographic differences in egg mass; eggs were smallest in South Africa despite small clutch sizes. These small eggs might be explained by high nest predation rates in South Africa; life-history theory predicts reduced reproductive effort under high risk of offspring mortality. This prediction was supported for clutch mass, which was inversely related to nest predation but not for egg mass. Nevertheless, clutch mass variation was not fully explained by nest predation, possibly reflecting interacting effects of adult mortality. Tests of the possible effects of nest predation on egg mass were compromised by limited power and by counterposing direct and indirect effects. Finally, components of parental investment, defined as effort per offspring, might be expected to positively coevolve. Indeed, egg mass, but not clutch mass, was greater in species that shared incubation by males and females compared with species in which only females incubate eggs. However, egg and clutch mass were not related to effort of parental care as measured by incubation attentiveness. Ecological and life-history correlates of egg and clutch mass variation found here follow from theory, but possible evolutionary causes deserve further study.
\end{abstract}

Key words.-Allometry, birds, clutch size, egg mass, nest predation, trade-offs.

Received July 28, 2005. Accepted November 23, 2005.

Egg mass varies among species in relation to body mass for diverse taxa (Rahn et al. 1985; Saether 1987; Berrigan 1991; Poiani and Jermiin 1994; Simpson 1995). Body mass only explains part of egg mass variation, however, and both the extent and causes of residual variation remain unclear. Egg mass might be expected to vary geographically, given geographic variation in life-history strategies and the potentially integral role of egg mass in these strategies (Lack 1968; Roff 1992; Martin et al. 2000; Martin 2002). Yet, broad geographic studies of egg-mass variation and its relationship to life-history variation are lacking. Indeed, even the geographic patterns of variation remain poorly studied and unclear. For example, intraspecific studies of mosquitoes, frogs, and lizards found decreasing egg mass with decreasing latitude (e.g., Forsman and Shine 1995; Gollman and Gollman 1996; Armbruster et al. 2001), while intraspecific studies of fish found

\footnotetext{
${ }^{4}$ Present Address: Department of Biology, University of California, Riverside, California 92521.

10 Present Address: FA 133-A, MS 314, Department of Biology, University of Nevada, Reno, Nevada 89557.
}

the contrasting pattern of larger and fewer eggs at lower latitudes (Fleming and Gross 1990; Johnston and Leggett 2002). The only interspecific study of geographic variation that we found was for frogs, which had larger eggs at lower latitudes within Australia (Morrison and Hero 2003). Are larger eggs at lower latitudes a common pattern across species? Or, does the pattern vary, as in intraspecific studies? Cross-continental interspecific variation is undescribed for any taxa, and causes of any such variation are unexplored. To improve understanding of the extent and causes of egg mass variation, studies of broad geographic variation are needed that simultaneously explore ecological and life-history correlates.

Here we describe broad patterns of geographic variation in egg mass in birds and test alternative hypotheses for this variation. We examine life-history correlates because egg mass may trade off and coevolve with other life-history traits (e.g., clutch size, parental care behavior) as part of an overall life-history strategy (Roff 1992). Indeed, egg mass might not evolve independently of total reproductive effort (Winkler and Wallin 1987; Schwarzkopf et al. 1999; Caley et al. 2001; 
Czesak and Fox 2003). In this regard, clutch mass (summed mass of all eggs in a clutch) might provide a better indicator of reproductive effort (e.g., Schwarzkopf et al. 1999; Caley et al. 2001) because it incorporates both the total energetic outlay for egg production and the number of young requiring parental care. Consequently, egg mass may coevolve with clutch mass, and we explore both here. Ultimately, ecological factors (e.g., resource limitation, nest predation, adult mortality) may exert direct selection on the evolution of egg and clutch mass, but they may also act indirectly through selection on trade-offs in overall life-history strategies. Thus, we explore multiple alternative hypotheses at both of these levels.

\section{Clutch size trade-off}

A central hypothesis of life-history theory is a trade-off between egg mass and clutch size (Smith and Fretwell 1974; Sinervo and Licht 1991; reviewed in Roff 1992). Most tropical and Southern Hemisphere species produce smaller clutch sizes than their northern relatives (Roff 1992; Martin et al. 2000; Ghalambor and Martin 2001), which might result in increased egg mass (for similar predictions from $r$ - $K$ theory see Cody 1966; MacArthur and Wilson 1967; Pianka 1970, 1972). Yet, the hypothesized trade-off between egg mass and number is assumed to be driven by partitioning of fixed finite resources between number versus mass (Smith and Fretwell 1974; Bernardo 1996). Trade-offs may not be expected, and instead positive covariation of resource-based traits (i.e., egg mass and number) may be expected if species differ in resource acquisition skills (Rose and Charlesworth 1981; Reznick 1985; Van Noordwijk and deJong 1986; Bernardo 1996). Similarly, selection may act on total reproductive effort and obfuscate trade-offs between egg mass and clutch size (Schwarzkopf et al. 1999; Czesak and Fox 2003). Interspecific trade-offs of egg mass with clutch size have not been found within various groups of birds, or they have been controversial because of possible confounding factors (Lack 1968; Saether 1987; Rohwer 1988, 1991; Blackburn 1991a,b; Poiani and Jermiin 1994). A more careful analysis is needed that accounts for possible confounding factors while testing trade-offs across diverse species and geographic regions.

\section{Parental care}

In many organisms, including birds, parental care represents an important component of reproductive effort. Selection for increased reproductive effort might favor correlated selection on components of reproductive effort (Winkler and Wallin 1987; Roff 1992; Schwarzkopf et al. 1999; Caley et al. 2001; Czesak and Fox 2003). Consequently, parental care effort may be positively associated with egg and clutch mass (Shine 1978; Sargent et al. 1987; Nussbaum and Schultz 1989), although such correlations are not always found (e.g., Simpson 1995; Ruber et al. 2004). Nest attentiveness (percentage of time that parents sit on the nest incubating eggs) is an important component of reproductive effort that varies among songbird species (Martin 2002). Egg and clutch mass therefore might be expected to increase with nest attentiveness. Selection may act on parental investment (i.e., effort invested per offspring) rather than total reproductive effort, however, and components of parental investment might be expected to coevolve positively. Thus, egg mass as a component of parental investment might covary positively with other parental investment tactics that increase the level of care received by the eggs rather than effort per se. Bird species differ in whether only one sex or both sexes incubate. The total level of care (i.e., attentiveness), but not female effort, increases with biparental incubation (Skutch 1957). Thus, we examine whether egg and clutch mass are larger in species with greater effort or tactics (shared incubation) that increase levels of parental care.

\section{Nest predation}

Increased egg predation can directly favor reduced reproductive investment, which might be reflected as reduced egg mass, clutch size, or clutch mass (Slagsvold 1982, 1984; Martin 1995; Martin et al. 2000; Fontaine and Martin 2006). However, if clutch size trades off with egg mass and nest predation influences clutch size (e.g., Martin 1995; Martin et al. 2000), nest predation might indirectly affect egg mass by directly affecting clutch size. Such effects of predation risk on egg and clutch mass variation are unexplored (but see Fontaine and Martin 2006).

\section{Adult mortality}

Reproductive effort is expected to decrease with reduced adult mortality (Williams 1966; Roff 1992; Charlesworth 1994; Martin 1995, 2002). As a result, reduced adult mortality might favor allocation of fewer total resources through smaller clutch size and clutch mass, but greater parental investment (i.e., larger egg mass) to increase the quality of individual offspring (Cody 1966; MacArthur and Wilson 1967; Pianka 1970, 1972; Promislow and Harvey 1990; Roff 1992). In other words, clutch size and clutch mass might be positively related and egg mass negatively related to adult mortality (also see Winkler and Wallin 1987) not because of a trade-off between clutch size and egg mass, but because of correlated selection from adult mortality. These theoretical predictions are relatively untested.

Here, we examine the potential influence of these important sources of selection and trade-offs on interspecific variation in egg and clutch mass among 74 passerine species studied at four latitudes and sites (United States, Venezuela, Argentina, South Africa) on three continents. Passerine species are the focus of this study because they represent a single avian order, thereby reducing possible phylogenetic effects. At the same time, passerines include almost the entire gradient of clutch size and other life-history variation seen among birds in general, while minimizing confounding factors such as precocial hatching and extreme differences in foraging and nestling feeding strategies (Martin 2004). We first describe geographic variation in allometric relationships and then explore possible life-history and ecological correlates of residual egg mass variation within and among geographic locations.

\section{Materials And Methods}

Study sites were chosen as part of a broader life-history study of species with diverse life-history strategies within 
and among latitudes: north temperate, tropical, southern subtropical, and south temperate. North temperate study sites in Arizona $\left(34^{\circ} \mathrm{N}\right.$ latitude) were high-elevation $(2300 \mathrm{~m})$ forest drainages of mixed conifer and deciduous canopy tree species (Martin 1998). Tropical study sites in Venezuela $\left(9^{\circ} \mathrm{N}\right.$ latitude) were cloud forest (1600-2000 m elevation) in Yacambu National Park near the northern end of the Andes. Subtropical study sites in northwestern Argentina ( $24^{\circ} \mathrm{S}$ latitude) were Yungas forest habitat (1000-1250 m elevation) in El Rey National Park (Martin et al. 2000). South temperate study sites in South Africa (sea level and $34^{\circ} \mathrm{S}$ latitude) were in coastal shrubland at Koeberg Nature Reserve near Cape Town.

Nests were located and monitored to obtain data on egg mass, clutch size, clutch mass, nest predation rates, and parental care behaviors to test the alternative hypotheses outlined above. Nests were sampled during May-July 19882004 in Arizona, March-July 2002-2005 in Venezuela, October-January 1997-2000 in Argentina, and August-November 2000-2004 in South Africa. A total of 18,208 nests were studied for species included here: Arizona (9578), Venezuela (1342), Argentina (1268), and South Africa (6020).

Egg mass was taken from a subset of nests found during nest-building or egg-laying. To minimize any mass reduction from water loss, egg mass was measured within three days of clutch completion, using portable electronic balances (0.001 g precision; Acculab, Edgewood, NY). Egg mass was measured at an average of 21 nests per species (range 1-87 nests per species; 1541 total). Data were used for species with sample sizes as small as one nest because egg mass varies substantially less within species than among species (e.g., Marshall and Gittleman 1994; Bonduriansky and Brooks 1999); the coefficient of variation of egg mass within species was almost always less than 9\% (T. E. Martin, unpubl. data), whereas egg mass varied by $1000 \%$ among species. Moreover, sample size did not explain any of the residual variation in egg mass $\left(F_{1,67}=0.07, P=0.80\right)$ in the full analysis of covariance (ANCOVA) model that included site, body mass, and clutch size (see Results).

We visited nests every one to four days to determine clutch size and nest fate. Clutch size was measured as the final number of eggs laid and seen on two different days. Nests were considered successful if we observed nestlings within two days of fledging age, fledglings near the nest, or parents feeding new fledglings in the general area of the nest. Predation was assumed when nest contents disappeared before young were old enough to fledge. Daily survival and predation rates were estimated following Mayfield (1975), Johnson (1979), and Hensler and Nichols (1981), but they were only calculated for species with sample sizes greater than 18 nests.

Nest attentiveness was measured as the percent of time birds were on the nest incubating eggs. Nests were videotaped during incubation for the first 6-7 $\mathrm{h}$ of the day, beginning within $0.5 \mathrm{~h}$ of sunrise from 1993 to 2004 in Arizona and in all study years in Argentina, Venezuela, and South Africa. This protocol provided data on incubation behavior and nest attentiveness averaged over the first 6-7 h of each day and standardized for both time of day and sampling duration (Martin et al. 2000; Martin 2002).
Adult mortality probabilities for Arizona and Argentina are from Martin (2002). For South Africa, we used adult mortality estimates for the same species or closely related congeners estimated by Peach et al. (2001) from a different location. We used these estimates because the partial correlation $\left(R_{p}=0.92, \mathrm{df}=7, P=0.003\right)$ between clutch sizes of our South African study species and adult mortality estimates from Peach et al. (2001) corrected for body mass suggest that the estimates are reasonable. Adult mortality estimates from Venezuela are not yet available.

We examined geographic differences in log-log allometric relationships for egg and clutch mass using ANCOVA, where location was included as a random factor and log-transformed body mass was a covariate. Slopes did not differ among sites (see Results), so differences among sites were tested for each trait corrected for body mass using the least significant difference (LSD) test that adjusts for multiple comparisons. We only report and include significant interactions.

We controlled for possible phylogenetic effects using independent contrasts (Felsenstein 1985) based on the CRUNCH option of program CAIC (Purvis and Rambaut 1995). The phylogenetic hypothesis was based on Sibley and Ahlquist (1990) but updated by subsequent studies summarized in Martin (1995) and Martin et al. (2000) or published more recently (Barker et al. 2002; Birdsley 2002; Lovette and Bermingham 2002; Outlaw et al. 2003; Chesser 2004; Cibois and Cracraft 2004). We used a regression approach for all partial correlation analyses as well as for ANCOVA, in which location was used as a set of three dummy variables in independent contrasts (Martin 1995). All regressions were forced through the origin (Harvey and Pagel 1991). Analyses were conducted using both equal branch lengths and branch lengths estimated by distance of species along the phylogeny (Purvis and Rambaut 1995). We report only the analyses using raw data because all results were the same as those using both sets of independent contrasts.

\section{Results}

Mean egg mass varied by an order of magnitude across our study species, from $0.78 \mathrm{~g}$ for Anthoscopus minutus in South Africa to $7.8 \mathrm{~g}$ for Turdus serranus in Venezuela. The slopes of egg mass with body mass did not differ among sites (Fig. $1 \mathrm{~A} ; F_{3,66}=0.5, P=0.68$ ), with a common log-log slope (mean $\pm 1 \mathrm{SE}$ ) of $0.746 \pm 0.021$. Note that the slope is the $3 / 4$ exponent that often typifies metabolic processes scaling with body mass (Schmidt-Nielsen 1984; West et al. 1997, 1999). Because slopes did not differ, we removed the interaction term in subsequent analyses. Egg mass covaried with body mass (Fig. 1A; $F_{1,69}=1249, P<0.0001$ ) but differed among locations for a constant body mass $\left(F_{3,69}=35, P<\right.$ $0.0001)$. Relative egg mass was largest in tropical Venezuela and subtropical Argentina and smallest in south temperate South Africa and north temperate Arizona for the same body mass; for example, egg mass was $45 \%$ larger in Venezuela compared with South Africa for constant body mass (Fig. 2A).

Clutch mass increased with body mass (Fig. $1 \mathrm{~B} ; F_{1,69}=$ 507, $P<0.0001)$, and geographic locations differed from each other $\left(F_{3,69}=33, P<0.0001\right)$ with a common log-log 

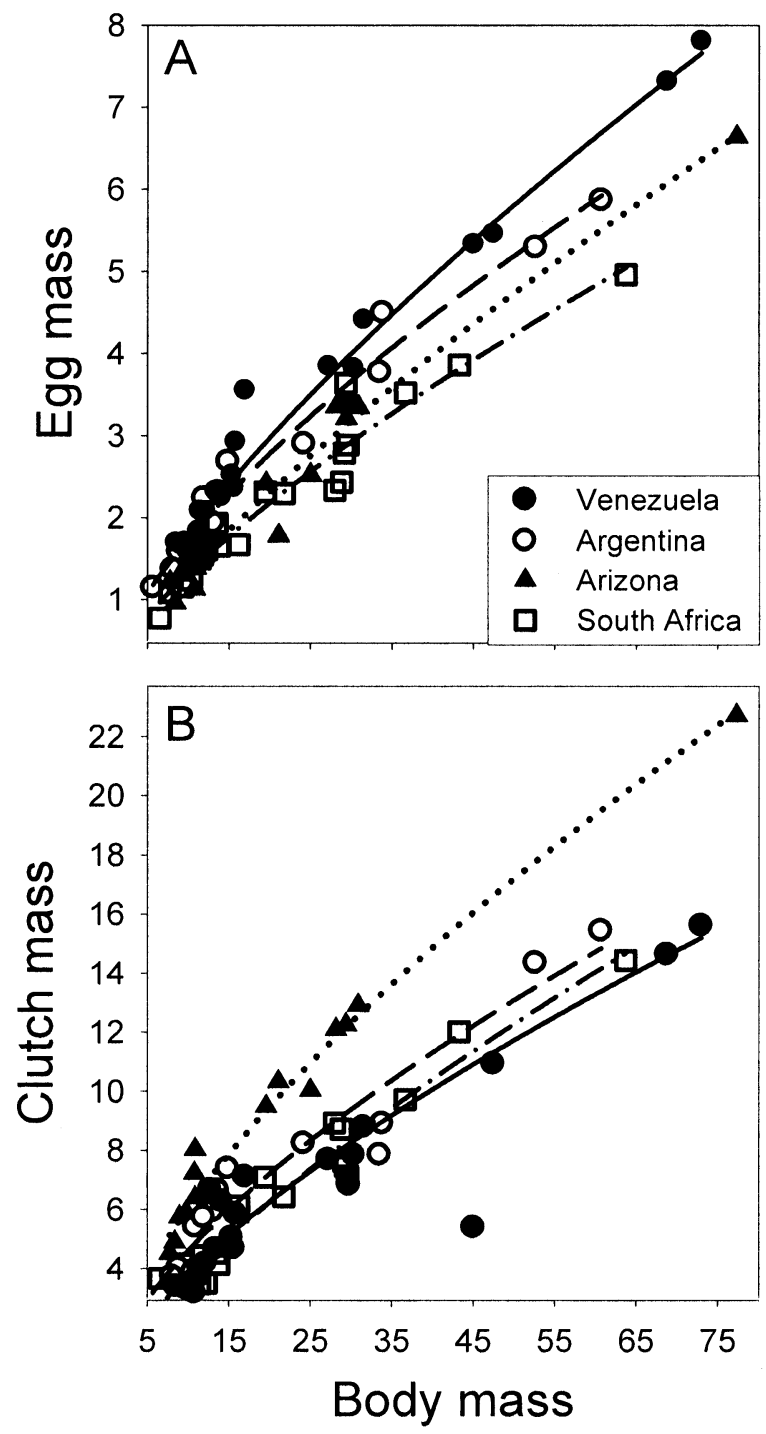

FIG. 1. Allometric relationships for 74 passerine species measured at four geographic locations between body mass and (A) egg mass and (B) clutch mass as the summed mass of all eggs in a clutch. The low outlier from Venezuela is Buarremon brunneinucha, which has a clutch size of one egg $(n=119$ nests). The lines reflect sites as follows: solid, Venezuela; dashed, Argentina; dotted, Arizona; dashed and dotted, South Africa.

slope (mean $\pm 1 \mathrm{SE}$ ) of $0.670 \pm 0.030$. Note that this slope is the $2 / 3$ scaling exponent that has been observed and proposed as an alternative to the $3 / 4$ exponent (Dodds et al. 2001; White and Seymour 2003). Clutch mass was smallest in tropical Venezuela and south temperate South Africa, intermediate in Argentina, and largest in north temperate Arizona for the same body mass (Figs. 1B, 2B). Thus, egg and clutch mass did not exhibit the same patterns among geographic locations; egg mass was largest in tropical Venezuela, where clutch mass was smallest, and egg mass was small in north temperate Arizona, where clutch mass was largest. Argentina, was intermediate, and South Africa had both small egg and clutch mass (Figs. 1, 2).

The different patterns of egg and clutch mass reflected an interaction of clutch size variation; clutch size differed among
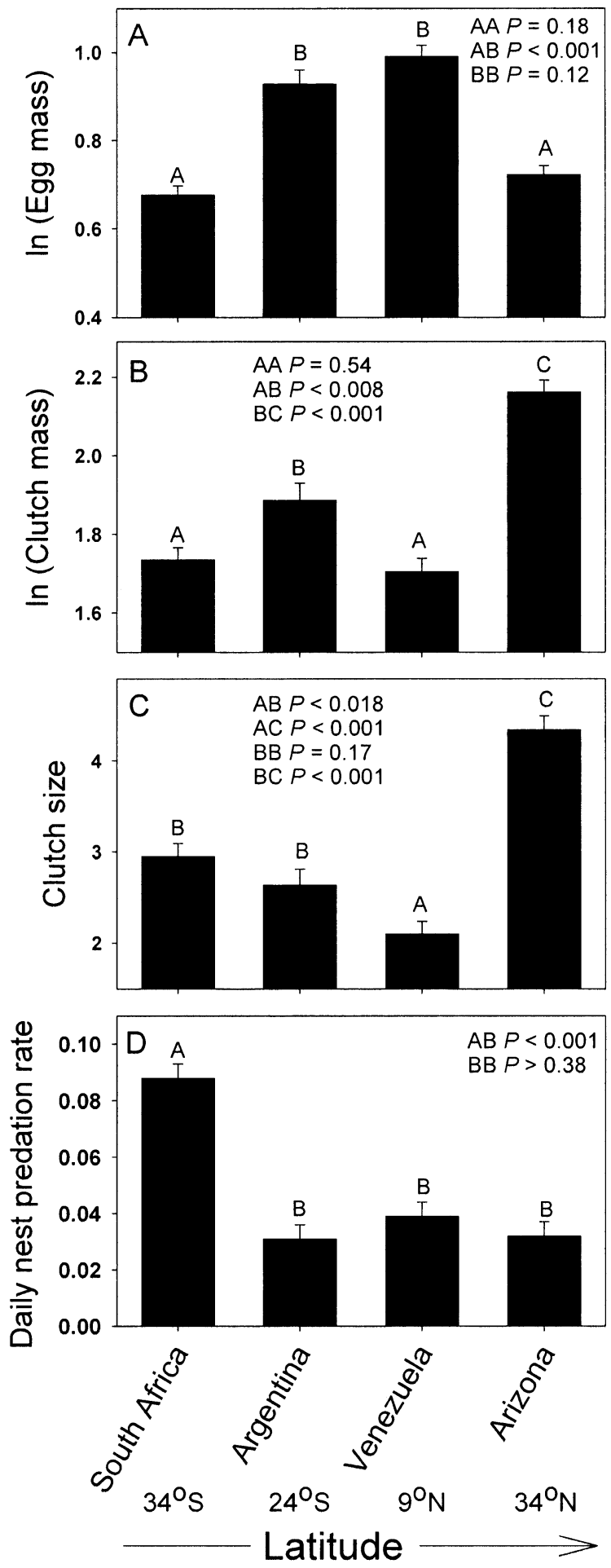

FIG. 2. Estimated marginal means $( \pm 1 \mathrm{SE})$ of life-history traits from analysis of covariance correcting for body mass across the four study locations. Different letters indicate means that are significantly different based on least significant difference post hoc tests, as described in each cell. (A) Egg mass corrected for body mass in a log-log analysis; (B) clutch mass corrected for body mass in a log-log analysis; (C) clutch size corrected for log-transformed body mass; and (D) daily nest predation rate (the daily probability that a nest will be depredated). 
sites (Fig. 2C; $F_{3,69}=39, P<0.0001$ ) after controlling for a mild negative relationship with log-transformed body mass $\left(F_{1,69}=4.2, P=0.044\right)$. Arizona had substantially larger clutch sizes than all other sites; South Africa did not differ from Argentina, but South Africa and Argentina were larger than Venezuela (Fig. 2C). The variation in clutch size apparently contributed to geographic variation in egg mass; egg mass was negatively related to clutch size (Fig. $3 \mathrm{~A} ; F_{1,68}=$ $54, P<0.0001)$ within and among sites $\left(F_{3,68}=30, P<\right.$ $0.0001)$ after allometry was taken into account $\left(F_{1,68}=1929\right.$, $P<0.0001)$. Site was a significant factor only because of South Africa, where egg mass was smaller for a given clutch size compared to all other sites (Fig. 3A); if South Africa was excluded from analyses, then egg mass was still negatively related to clutch size $\left(F_{1,49}=30, P<0.0001\right)$ and positively related to body mass $\left(F_{1,49}=1195, P<0.0001\right)$, but sites did not differ from each other $\left(F_{2,49}=0.07, P=\right.$ $0.94)$.

Egg mass did not covary with reproductive effort as reflected by clutch mass $\left(F_{1,60}=1.2, P=0.27\right)$ when included in its full model (site, body mass, nest predation). Egg mass also was not related to parental care effort as reflected by nest attentiveness $\left(F_{1,62}=0.3, P=0.61\right)$ when included in its full model (site, body mass, clutch size, shared incubation).

Species in which males and females shared incubation ( $n$ $=13$ ) produced larger eggs than species with female-only incubation $\left(F_{1,67}=5.9, P=0.018\right)$ even after site $\left(F_{3,67}=\right.$ $33, P<0.0001)$, body mass $\left(F_{1,67}=2071, P<0.0001\right)$, and clutch size $\left(F_{1,67}=53, P<0.0001\right)$ were taken into account. Shared incubation did not explain clutch mass $\left(F_{1,63}=0.4\right.$, $P=0.55$ ) when included in its full model (site, body mass, nest predation). Thus, evolution of a tactic (i.e., biparental incubation) that increases parental care without increasing female effort is associated with increased parental investment (i.e., larger eggs) but not increased reproductive effort (clutch mass and incubation effort).

Nest predation tended to be positively related to body mass $\left(F_{1,65}=5.4, P=0.054\right)$, and differed among sites $\left(F_{3,65}=\right.$ $34, P<0.0001)$. South Africa had substantially higher nest predation than all other sites, and the three remaining sites did not differ from each other (Fig. 2D). When egg mass was corrected for body mass and clutch size, the residual variation was strongly correlated with nest predation across sites $\left(R_{p}\right.$ $=-0.64, \mathrm{df}=66, P<0.0001$; see gray line in Fig. 3B). However, negative relationships were not consistently displayed within all sites (Fig. 3B), and the lack of difference in nest predation among three sites (Fig. 2D) caused the smaller egg mass and high nest predation in South Africa to have a disproportionate effect across sites (Fig. 3B). Nest predation did not explain additional variation $\left(F_{1,63}=0.01\right.$, $P=0.91)$ in egg mass after site $\left(F_{3,63}=12, P<0.0001\right)$, body mass $\left(F_{1,63}=1967, P<0.0001\right)$, and clutch size $\left(F_{1,63}\right.$ $=38, P<0.0001)$ were taken into account. However, nest predation had a strong influence on clutch size $\left(F_{1,64}=24\right.$, $P<0.0001$ ) within and among sites (site: $F_{3,64}=57, P<$ 0.0001 ; body mass: $F_{1,64}=1.0, P=0.32$ ), suggesting a possible indirect effect of nest predation on egg mass, given the inverse relationship between egg mass and clutch size (Fig. 3A). Moreover, clutch mass was negatively related to
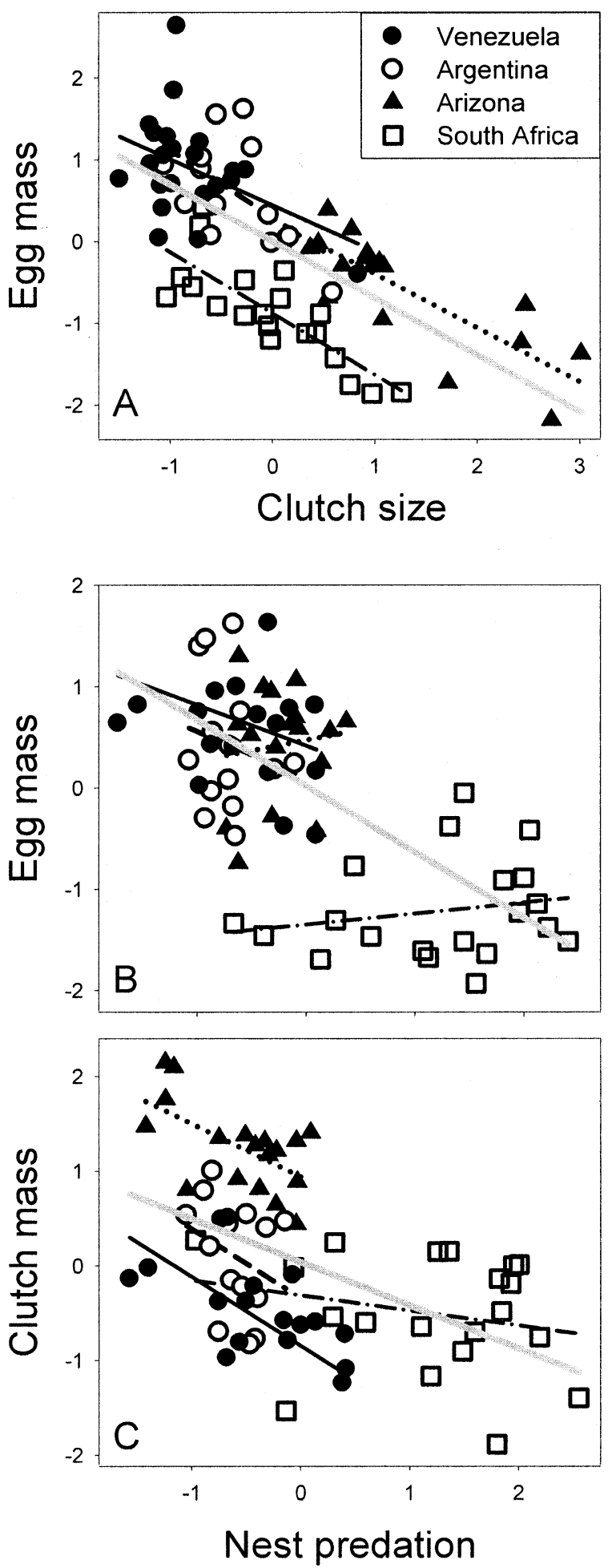

FIG. 3. Relationships between (A) residuals of egg mass (g) and clutch size, each corrected for adult body mass (g); (B) residuals of egg mass (g) corrected for adult body mass (g) and clutch size relative to daily nest predation rate corrected for clutch size; and (C) residuals of clutch mass and daily nest predation rate, each corrected for adult body mass. Regression lines for individual sites only span the variation for the site, whereas the correlation across sites is reflected by the gray line that spans the entire gradient. The lines reflect sites as follows: solid, Venezuela; dashed, Argentina; dotted, Arizona; dashed and dotted, South Africa. 

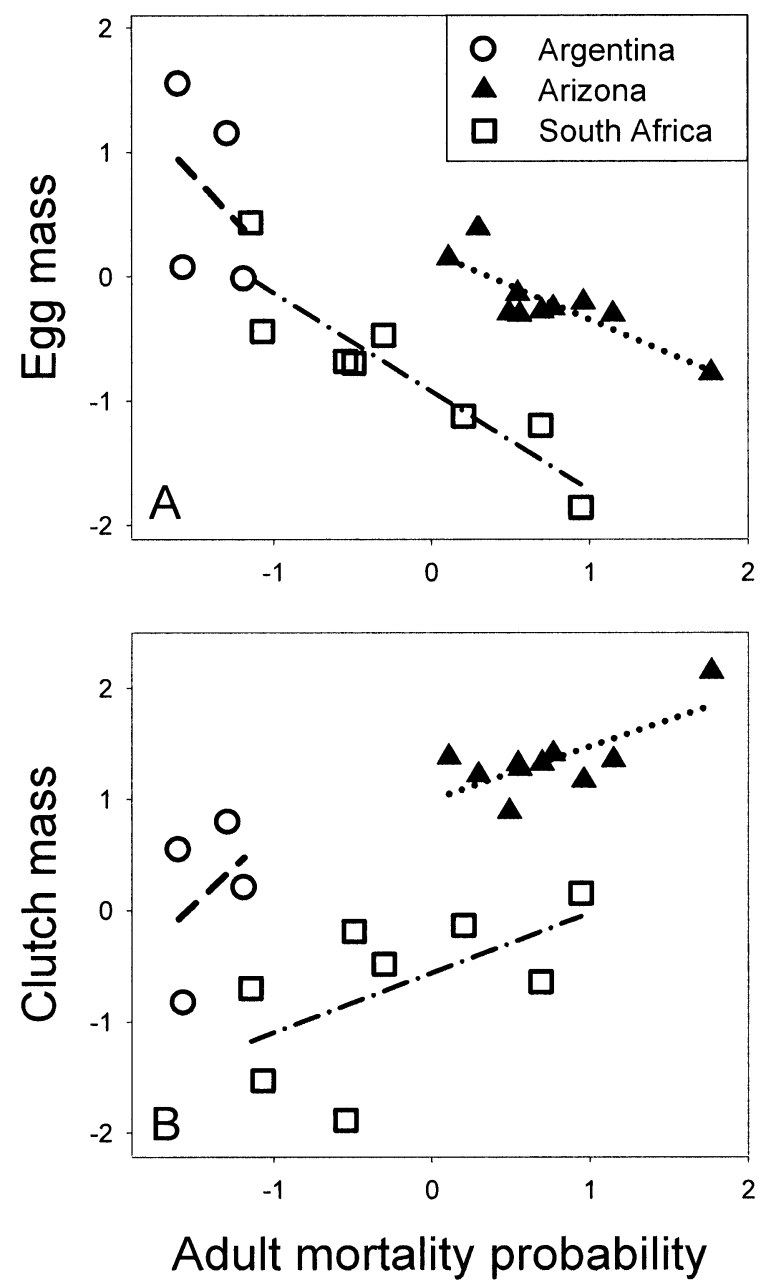

FIG. 4. Relationships between residuals of (A) egg mass (g) and (B) clutch mass (g) relative to adult mortality probability, with all variables corrected for adult body mass. The lines reflect sites as follows: dashed, Argentina; dotted, Arizona; dashed and dotted, South Africa.

nest predation $\left(F_{1,64}=9.2, P=0.004\right)$, even when site $\left(F_{3,64}\right.$ $=27.9, P=0.001)$ and body mass $\left(F_{1,64}=603, P<0.0001\right)$ were taken into account (Fig. 3C). However, clutch mass still differed among sites for the same nest predation rate (Fig. 3C). Thus, increased nest predation appears to favor reduced reproductive effort, as reflected by smaller clutch sizes and clutch masses, and may indirectly influence egg mass through direct effects on clutch size (i.e., Fig. 3A), but direct effects of nest predation on egg mass are unclear.

Egg mass was negatively related to adult mortality (Fig. $\left.4 \mathrm{~A} ; F_{1,17}=22.9, P<0.0001\right)$ in the three sites with data (Arizona, Argentina, South Africa), even after site $\left(F_{2,17}=\right.$ 18.0, $P<0.0001)$ and body mass $\left(F_{1,17}=795, P<0.0001\right)$ were taken into account. Clutch size was not significant $\left(F_{1,16}\right.$ $=0.008, P=0.93)$ in explaining variation in egg mass because of the strong relationship between clutch size and adult mortality $\left(F_{1,17}=39.1, P<0.0001\right)$ regardless of body mass $\left(F_{1,17}=1.1, P=0.30\right)$ or site $\left(F_{2,17}=8.5, P=0.003\right)$. Thus, clutch size and adult mortality were effectively redundant at this small sample size, and independent effects could not be adequately tested. Clutch mass was positively related to adult mortality (Fig. $4 \mathrm{~B} ; F_{1,16}=7.4, P=0.015$ ) even after site $\left(F_{2,16}=5.9, P=0.012\right)$ and body mass $\left(F_{1,16}=\right.$ $183, P<0.0001)$ were taken into account, but nest predation did not explain additional variation $\left(F_{1,16}=0.2, P=0.69\right)$. In short, the results followed predictions: increased adult mortality was associated with increased reproductive effort, as reflected by larger clutch sizes and clutch masses, but was associated with lower parental investment (i.e., effort per offspring), as reflected by smaller eggs.

\section{Discussion}

Egg mass varied strongly with body mass, as previously documented in a variety of taxa (Rahn et al. 1985; Saether 1987; Berrigan 1991; Poiani and Jermiin 1994), and clutch mass showed an equally strong relationship with body mass (Fig. 1). However, once body mass was taken into account, considerable residual variation remained. Indeed, egg and clutch mass clearly differed among geographic locations for a constant body size, demonstrating that egg and clutch mass evolved to some extent independent of body mass among regions (Figs. 1, 2), and this variation was associated with life-history and ecological correlates.

Egg mass varied inversely with clutch size within and among sites (Fig. 3A), as predicted by theory (Smith and Fretwell 1974) and found by Blackburn (1991a), but contrasting with other tests in birds (e.g., Saether 1987; Rohwer 1988; Poiani and Jermiin 1994). This relationship explained considerable variation in egg mass within all sites and was able to explain a substantial amount of geographic variation in egg mass across three sites. However, the clutch size tradeoff did not explain all geographic variation, because South African birds produced small eggs (Fig. 2A) despite also producing small clutches (Fig. 2C), which are typical of Southern Hemisphere birds (Martin 2002). Consequently, they had smaller eggs for a given clutch size than all other sites (Fig. 3A). Thus, clutch size is an important correlate of geographic variation in egg mass, but additional factors must also contribute to geographic variation.

The coevolution of egg mass with other life-history tactics is indicated by the evolution of larger eggs in species that evolved biparental incubation, as we document for the first time. Shared incubation increases overall parental care (i.e., total nest attentiveness) received by eggs, but may actually reduce parental effort of females because females incubate less when incubation is shared by both parents than when they incubate alone (Skutch 1957; T. E. Martin, unpubl. data). The increase in egg mass with evolution of a tactic (i.e., shared incubation) that increases total care but not female effort suggests that egg mass is not simply coevolving with reproductive effort. Indeed, the absence of relationships between egg mass and clutch mass or nest attentiveness, both of which represent important components of reproductive effort, clearly argues against the notion that egg mass is simply coevolving with reproductive effort.

Increased nest predation was associated with reduced reproductive effort, as reflected by both clutch size and clutch mass, and as predicted (Martin 1995, 2002; Martin et al. 2000), but effects of nest predation on egg mass were less 
obvious. The small eggs in South Africa might reflect reduced investment in response to the very high nest predation rates there (Fig. 2D), as suggested by the cross-site correlation (Fig. 3B). Indeed, experimental alteration of nest predation risk for eight songbird species in Arizona yielded smaller eggs and no change in clutch size on plots with higher risk (Fontaine and Martin 2006), demonstrating that birds will reduce egg mass in direct response to increased nest predation risk. The small clutch sizes of many of the South African birds do not leave much flexibility to reduce clutch size further in response to high nest predation; instead, egg mass may then be reduced, as seen by Fontaine and Martin (2006). Nonetheless, the possible role of nest predation in influencing egg mass across regions remains uncertain because three of the sites did not differ in nest predation (Fig. 2D), and the cross-site correlation is the result of South Africa differing from the other three sites (Fig. 3B). Thus, we need additional studies across more sites that differ in nest predation rates to clarify the potential role of nest predation in contributing to geographic variation in egg mass.

Egg mass did not vary with nest predation within sites (Fig. 3B). The absence of a correlation between nest predation and egg mass within sites raises questions as to the importance of nest predation on egg mass within regions. However, direct effects of nest predation favoring reduced egg mass are difficult to test because of potential counterposing direct and indirect effects. Increased nest predation may directly favor reduced investment in the current clutch through reduced egg mass (Fontaine and Martin 2006), but indirectly favor larger eggs by directly favoring smaller clutch sizes (see Results; Martin 1995; Martin et al. 2000) that are associated with larger eggs (Fig. 3A). Nest predation might influence clutch size over egg mass because smaller clutches represent a more significant reduction in energetic investment (i.e., fewer eggs to produce, incubate, and young to feed) than simply reducing egg size. The resulting indirect effect of nest predation favoring smaller clutches that are associated with larger eggs opposes direct effects favoring smaller eggs, and thereby complicates detection of nest predation effects. In regions (e.g., Venezuela) where clutch size is already extremely small, however, nest predation may show a clearer effect on egg mass. Such possibilities need further tests.

The possible influence of adult mortality raises interesting alternative explanations for the inverse relationship between clutch size and egg mass. This inverse relationship is commonly thought to reflect partitioning of fixed finite resources between number versus mass (Smith and Fretwell 1974; Bernardo 1996). Such interpretations are one possibility. Yet, egg production is only a small component of the energy required by birds with altricial young, which expend much more energy on parental care (Martin 1987), and food limitation is unable to explain egg mass variation in birds (see Williams 2001; Christians 2002). Consequently, the inverse relationship between clutch size and egg mass may not necessarily reflect a resource-based trade-off so much as the evolution of alternative strategies. Life-history theory predicts lower reproductive effort in species with lower adult mortality and high likelihood of offspring mortality (Roff 1992; Charlesworth 1994; Martin 2002, 2004), which was clearly observed here in terms of smaller clutches and clutch masses (Fig. 4B). At the same time, low adult mortality may favor simultaneous evolution of increased parental investment (i.e., more resources manifested as larger eggs) in the smaller number of propagules to enhance offspring quality and longevity (see also Cody 1966; MacArthur and Wilson 1967; Pianka 1970, 1972). The inability of food limitation to explain egg mass variation (Williams 2001; Christians 2002) bolsters the possibility that the inverse relationship between clutch size and egg mass does not reflect a resourcebased trade-off, but instead reflects inversely correlated selection on these two life-history traits.

The problem with this explanation is that existing correlative and experimental evidence suggests that larger eggs do not confer clear lasting fitness benefits in terms of offspring survival in birds (reviewed in Williams 1994; Christians 2002; Krist et al. 2004). However, possible contributions of larger eggs to enhanced internal development (e.g., immune function, cellular processes) that might improve longevity are unknown. The negative association of egg mass with adult mortality (Fig. 4A) indicates that longer-lived species invest more in individual progeny, and such investment needs explanation. However, the smaller eggs of South African species for a given adult mortality (i.e., Fig. 4A) indicate that adult mortality alone does not explain geographic variation in egg mass, similar to the inability of clutch size to explain South African egg mass. Moreover, given that clutch size is strongly related to adult mortality (Martin 1995, 2002; Ghalambor and Martin 2001), it is difficult to know whether clutch size or adult mortality is the actual factor shaping egg mass, especially given the limited sample size of species with adult mortality data.

Finally, temperature is another factor that has been argued to influence geographic variation in egg mass, at least in ectotherms (Forsman and Shine 1995; Gollman and Gollman 1996; Armbruster et al. 2001; Morrison and Hero 2003). Ambient temperature is unlikely to be important in birds because parents modify the temperature experienced by eggs. Moreover, mean temperatures during the study seasons were not significantly different among sites: South Africa $\left(15.1^{\circ} \mathrm{C}\right)$, Arizona $\left(15.8^{\circ} \mathrm{C}\right)$, Venezuela $\left(15.8^{\circ} \mathrm{C}\right)$, and Argentina $\left(18.0^{\circ} \mathrm{C}\right)$. Thus, temperature seems unlikely to explain the egg mass variation documented here.

Ultimately, these data show that significant geographic variation in egg mass has evolved, although characterization of this variation across more species and locations is needed to further examine possible causes. Some of the variation is associated with the evolution of different life-history traits and parental care behaviors, and some is associated with either adult mortality or reproductive effort, but the roles of number (i.e., clutch size) versus adult mortality and possible effects of nest predation need further study, as do the possible effects of egg mass on internal development and long-term fitness.

\section{ACKNOWLEDGMENTS}

We are grateful for helpful comments from three anonymous reviewers, L. S. Forbes, and C. Benkman. We also thank numerous field assistants for help in the field, and C. Spottiswoode for help with phylogenetic analyses. This work 
was supported by grants from the National Science Foundation (DEB-9707598, INT-9906030, DEB-9981527), the International Program of the U.S. Fish and Wildlife Service, the USGS Global Change Research Program, and the National Research Initiative of the USDA Cooperative State Research, Education, and Extension Service program (grant 2005-02817).

\section{Literature Cited}

Armbruster, P., W. E. Bradshaw, K. Ruegg, and C. M. Holzapfel. 2001. Geographic variation and the evolution of reproductive allocation in the pitcher-plant mosquito, Wyeomyia smithii. Evolution 55:439-444.

Barker, F. K., G. F. Barrowclough, and J. G. Groth. 2002. A phylogenetic hypothesis for passerine birds: taxonomic and biogeographic implications of an analysis of nuclear DNA sequence data. Proc. R. Soc. B 269:295-308.

Bernardo, J. 1996. The particular maternal effect of propagule size, especially egg size: patterns, models, quality of evidence and interpretations. Am. Zool. 36:216-236.

Berrigan, D. 1991. The allometry of egg size and number in insects. Oikos 60:313-321.

Birdsley, J. S. 2002. Phylogeny of the tyrant flycatchers (Tyrannidae) based on morphology and behavior. Auk 119:715-734.

Blackburn, T. M. 1991a. An interspecific relationship between egg size and clutch size in birds. Auk 108:973-977.

1991b. The interspecific relationship between egg size and clutch size in wildfowl. Auk 108:209-211.

Bonduriansky, R., and R. J. Brooks. 1999. Reproductive allocation and reproductive ecology of seven species of Diptera. Ecol. Entomol. 24:389-395.

Caley, M. J., L. Schwarzkopf, and R. Shine. 2001. Does total reproductive effort evolve independently of offspring size? Evolution 55:1245-1248.

Charlesworth, B. 1994. Evolution in age structured populations. Cambridge Univ. Press, Cambridge, U.K.

Chesser, R. T. 2004. Molecular systematics of New World suboscine birds. Mol. Phylogenet. Evol. 32:11-24.

Christians, J. K. 2002. Avian egg size: variation within species and inflexibility within individuals. Biol. Rev. 77:1-26.

Cibois, A., and J. Cracraft. 2004. Assessing the passerine "tapestry"': phylogenetic relationships of the Muscicapoidea inferred from nuclear DNA sequences. Mol. Phylogenet. Evol. 32: 264-273.

Cody, M. L. 1966. A general theory of clutch size. Evolution 20: 174-184.

Czesak, M. E., and C. W. Fox. 2003. Evolutionary ecology of egg size and number in a seed beetle: genetic trade-off differs between environments. Evolution 57:1121-1132.

Dodds, P. S., D. H. Rothman, and J. S. Weitz. 2001. Re-examination of the "3/4-law" of metabolism. J. Theor. Biol. 209:9-27.

Felsenstein, J. 1985. Phylogenies and the comparative method. Am. Nat. 125:1-15.

Fleming, I. A., and M. R. Gross. 1990. Latitudinal clines: a tradeoff between egg number and size in Pacific salmon. Ecology 71: $1-11$.

Fontaine, J. J., and T. E. Martin. 2006. Reproductive responses to experimentally reduced nest predation risk among coexisting bird species. Ecol. Lett. In press.

Forsman, A., and R. Shine. 1995. Parallel geographic variation in body shape and reproductive life-history within the Australian scincid lizard Lampropholis delicate. Funct. Ecol. 9:818-828.

Ghalambor, C. K., and T. E. Martin. 2001. Fecundity-survival tradeoffs and parental risk-taking in birds. Science 292:494-497.

Gollman, B., and G. Gollman. 1996. Geographic variation of larval traits in the Australian frog Geocrinia victoriana. Herpetologica 52:181-187.

Harvey, P., and M. D. Pagel. 1991. The comparative method in evolutionary biology. Oxford Univ. Press, Oxford, U.K.

Hensler, G. L., and J. D. Nichols. 1981. The Mayfield method of estimating nesting success: a model, estimators and simulation results. Wilson Bull. 93:42-53.

Johnson, D. H. 1979. Estimating nest success: the Mayfield method and an alternative. Auk 96:651-661.

Johnston, T., and W. C. Leggett. 2002. Maternal and environmental gradients in the egg size of an iteroparous fish. Ecology 83: 1777-1791.

Krist, M., V. Remes, L. Uvirova, P. Nadvornik, and S. Bures. 2004. Egg size and offspring performance in the collared flycatcher (Ficedula albicollis): a within-clutch approach. Oecologia 140: $52-60$.

Lack, D. 1968. Ecological adaptations for breeding in birds. Methuen, London.

Lovette, I. J., and E. Bermingham. 2002. What is a wood-warbler? Molecular characterization of a monophyletic Parulidae. Auk 119:695-714.

MacArthur, R. H., and E. O. Wilson. 1967. The theory of island biogeography. Princeton Univ. Press, Princeton, NJ.

Marshall, S. D., and J. Gittleman. 1994. Clutch size in spiders: Is more better? Funct. Ecol. 8:118-124.

Martin, T. E. 1987. Food as a limit on breeding birds: a life-history perspective. Annu. Rev. Ecol. Syst. 18:453-487.

_- 1995. Avian life-history evolution in relation to nest sites, nest predation and food. Ecol. Monogr. 65:101-127.

1998. Are microhabitat preferences of coexisting species under selection and adaptive? Ecology 79:656-670.

_ - 2002. A new view for avian life-history evolution tested on an incubation paradox. Proc. R. Soc. B 269:309-316.

- 2004. Avian life-history evolution has an eminent past: Does it have a bright future? Auk 121:289-301.

Martin, T. E., P. R. Martin, C. R. Olson, B. J. Heidinger, and J. J. Fontaine. 2000. Parental care and clutch sizes in North and South American birds. Science 287:1482-1485.

Mayfield, H. 1975. Suggestions for calculating nest success. Wilson Bull. 87:456-466.

Morrison, C., and J.-M. Hero. 2003. Geographic variation in lifehistory characteristics of amphibians: a review. J. Anim. Ecol. 72:270-279.

Nussbaum, R. A., and D. L. Schultz. 1989. Coevolution of parental care and egg size. Am. Nat. 133:591-603.

Outlaw, D. C., G. Voelker, B. Mila, and D. J. Girman. 2003. Evolution of long-distance migration in and historical biogeography of Catharus thrushes: a molecular phylogenetic approach. Auk 120:299-310.

Peach, W. J., D. B. Hanmer, and T. B. Oatley. 2001. Do southern African songbirds live longer than their European counterparts? Oikos 93:235-249.

Pianka, E. R. 1970. On $r$ and $K$ selection. Am. Nat. 104:592-597. . 1972. $r$ and $K$ selection or $b$ and $d$ selection? Am. Nat. 106:581-588.

Poiani, A., and L. S. Jermiin. 1994. A comparative analysis of some life-history traits between cooperatively and non-cooperatively breeding Australian passerines. Evol. Ecol. 8:471-488.

Promislow, D. E. L., and P. H. Harvey. 1990. Living fast and dying young: a comparative analysis of life-history variation among mammals. J. Zool. 220:417-437.

Purvis, A., and A. Rambaut. 1995. Comparative analysis by independent contrasts (CAIC): an Apple Macintosh application for analysing comparative data. Comput. Appl. Biol. Sci. 11: 247-251.

Rahn, H., P. R. Sotherland, and C. V. Paganelli. 1985. Interrelationships between egg mass and adult body mass and metabolism among passerine birds. J. Ornithol. 126:263-271.

Reznick, D. 1985. Costs of reproduction: an evaluation of the empirical evidence. Oikos 44:257-267.

Roff, D. A. 1992. The evolution of life histories. Chapman and Hall, New York.

Rohwer, F. C. 1988. Inter- and intraspecific relationships between egg size and clutch size in waterfowl. Auk 105:161-176. . 1991. Response to T. M. Blackburn. Auk 108:211-213.

Rose, M. R., and B. Charlesworth. 1981. Genetics of life-history in Drosophila melanogaster. I. Sib analysis of adult females. Genetics 97:173-186. 
Ruber, L., R. Britz, H. H. Tan, P. K. L. Ng, and R. Zardoya. 2004. Evolution of mouthbrooding and life-history correlates in the fighting fish genus Betta. Evolution 58:799-813.

Saether, B. E. 1987. The influence of body weight on the covariation between reproductive traits in European birds. Oikos 48:79-88.

Sargent, R. C., P. D. Taylor, and M. R. Gross. 1987. Parental care and the evolution of egg size in fishes. Am. Nat. 129:32-46.

Schmidt-Nielsen, K. 1984. Scaling: Why is animal size so important? Cambridge Univ. Press, Cambridge, U.K.

Schwarzkopf, L., M. W. Blows, and M. J. Caley. 1999. Life-history consequences of divergent selection on egg size in Drosophila melanogaster. Am. Nat. 154:333-340.

Shine, R. 1978. Propagule size and parental care: the "safe harbor" hypothesis. J. Theor. Biol. 75:417-424.

Sibley, C. G., and J. E. Ahlquist. 1990. Phylogeny and classification of birds: a study in molecular evolution. Yale Univ. Press, New Haven, CT.

Simpson, M. R. 1995. Covariation of spider egg and clutch size: the influence of foraging and parental care. Ecology 76:795-800.

Sinervo, B., and P. Licht. 1991. Hormonal and physiological control of clutch size, egg size, and egg shape in side-blotched lizards (Uta stansburiana): constraints on the evolution of lizard life histories. J. Exp. Zool. 257:252-264.

Skutch, A. F. 1957. The incubation patterns of birds. Ibis 99:69-93.

Slagsvold, T. 1982. Clutch size variation in passerine birds: the nest predation hypothesis. Oecologia 54:159-169.

-1984. Clutch size variation of birds in relation to nest predation: on the cost of reproduction. J. Anim. Ecol. 53: 945-953.

Smith, C. C., and S. D. Fretwell. 1974. The optimal balance between the size and number of offspring. Am. Nat. 108:499-506.

Van Noordwijk, A. J., and G. de Jong. 1986. Acquisition and allocation of resources: their influence on variation in life-history tactics. Am. Nat. 128:137-142.

West, G. B., J. H. Brown, and B. J. Enquist. 1997. A general model for the origin of allometric scaling laws in biology. Science 276: $122-126$.

. 1999. The fourth dimension of life: fractal geometry and allometric scaling of organisms. Science 284:1677-1679.

White, C. R., and R. S. Seymour. 2003. Mammalian basal metabolic rate is proportional to body mass ${ }^{2 / 3}$. Proc. Natl. Acad. Sci. USA 100:4046-4049.

Williams, G. C. 1966. Natural selection, the cost of reproduction, and a refinement of Lack's principle. Am. Nat. 100:687-690.

Williams, T. D. 1994. Intraspecific variation in egg size and egg composition in birds: effects on offspring fitness. Biol. Rev. 68: $35-59$.

_- 2001. Experimental manipulation of female reproduction reveals an intraspecific egg size-clutch size trade-off. Proc. R. Soc. B 268:423-428.

Winkler, D. W., and K. Wallin. 1987. Offspring size and number: a life-history model linking effort per offspring and total effort. Am. Nat. 129:708-720.

Corresponding Editor: C. Benkman 